\title{
Concept Maps: A Tool to Prepare for High Fidelity Simulation in Nursing
}

\author{
Barbara J. Daley \\ University of Wisconsin - Milwaukee \\ bdaley@uwm.edu \\ Sarah Black Beman \\ St. Catherine University \\ Sarah Morgan \\ University of Wisconsin - Milwaukee \\ Linda Kennedy \\ Chamberlain University College of Nursing \\ Mandy Sheriff \\ University of Wisconsin - Milwaukee
}

\begin{abstract}
In this study, the use of concept mapping as a method to prepare for high fidelity simulated learning experiences was investigated. Fourth year baccalaureate nursing students were taught how to use concept maps as a way to prepare for high fidelity simulated nursing experiences. Students prepared concept maps for two simulated experiences including; 1. caring for patients with diabetes, and, 2. caring for patients with heart failure. Simulated learning experiences were video recorded and debriefing sessions were audio recorded. Following the simulation, three data analysis strategies were employed including analysis of the videos of the simulation, analysis of the audio recordings of the debriefing sessions and analysis of the concept maps. Additionally, videos from previous semesters where students did not create concept maps prior to simulations were reviewed. When comparing student behaviors to Tanner's (2006) Clinical Judgment Model, findings indicated that students who created concept maps prior to simulation demonstrated an increase in noticing behaviors, but that interpreting, responding and reflecting behaviors did not appear to increase. Students also reported a need to have concept maps introduced earlier in their curriculum and that the maps facilitated their learning most in complex, hard to understand clinical cases. This study has implications for simulation, curriculum and the role of concept mapping in the creation of student knowledge structures.
\end{abstract}

Keywords: Concept mapping, high fidelity simulations, nursing curriculum, clinical judgment 
Providing high-quality clinical experiences is a crucial component of nursing student development and education. Clinical practice experiences help students learn not only the procedures and tasks involved in nursing care, but also the critical thinking, assessment, analysis and decision-making skills. Over the last 10-15 years, nursing education has begun using high fidelity simulations as a teaching and learning strategy that can replicate clinical practice. In recent years nursing programs have relied more extensively on simulations due to limited clinical space, shortages of faculty, patient safety concerns of clinical agencies and difficulty gaining access to electronic medical records (National Council of State Boards of Nursing, 2014).

Gaba (2004) defined simulation as “... a technique, not a technology, to replace or amplify real experiences with guided experiences, often immersive in nature, that evoke or replicate substantial aspects of the real world in a fully interactive fashion" (p. i2). Previous research indicates that simulations can assist students in gaining confidence, increasing knowledge and improving clinical performance. Additionally, the National Council of State Boards of Nursing in a study that replaced up to $50 \%$ of actual clinical experiences with simulated learning experiences found, "substantial evidence that substituting high-quality simulation experiences for up to half of traditional clinical hours produces comparable end-of-program educational outcomes and new graduates that are ready for clinical practice" (pg. S3).

However, what is unclear in previous research is what teaching strategies can be used with simulation to enhance learning outcomes. Additionally, there has been little investigation of which learning strategies help prepare students for simulation. The purpose of this pilot study was to investigate the role that concept mapping played in assisting nursing students to prepare for simulation.

\section{Supporting Literature}

To investigate the use of concept mapping and high fidelity simulation a scholarship of teaching and learning (SoTL) approach was selected (Schulman, 2005). SoTL is defined as: "problem posing about an issue of teaching or learning, study of the problem through methods appropriate to disciplinary epistemologies, application of result to practice, communication of results, selfreflection and peer review" (Hutchings \& Cambridge, 1999, p.7). As pedagogical strategies concept mapping and simulation offer a unique way to foster the development of learning and the creation of meaning. This study is particularly important because the current focus in higher education has shifted to include a greater emphasis on learning. This shift from a teaching focus to a learning focus started when Barr \& Tagg (1995) called on institutions of higher education to shift from being institutions that provide instruction to institutions that exist to produce learning. Concept mapping and simulation offer practical strategies to foster the development of learning potential in nursing students.

Constructivist learning theory provides the overall conceptual framework for this SoTL investigation. Constructivist learning theory holds that "learners actively construct and reconstruct knowledge out of their experiences in the world" (Kafai \& Resnik, 2011). Knowledge construction takes place when learners actively build knowledge through intellectual engagement and investment in personally meaningful tasks. Constructivists believe that individuals learn through their experience and that meaning is rooted in that experience. The key to learning, in a constructivist framework, is

Journal of the Scholarship of Teaching and Learning, Vol. 17, No. 4, October 2017. josotl.indiana.edu 
for the learner to find multiple ways to link new information to previous knowledge and experience. Lambert et al. (1995) refer to constructivism as the epistemological processes of knowing and coming to know. Within a constructivist framework, learners create their own knowledge by how they put their worlds together. In other words, constructivists focus on the connections that the learner is making between ideas. Novak and Gowin (1984) and Novak (1998) believe that learning occurs through a process of assimilating concepts into the cognitive structures by either subsuming concepts under each other, progressively differentiating concepts from each other or reconciling the similarities between concepts. The crucial element is that the learner actively creates a knowledge base through linkages, the connections between ideas and the experiences.

Novak (1998) and Novak and Gowin (1984) operationalized constructivist learning theory by creating concept maps. A concept map is a "schematic device for representing a set of concept meanings embedded in a framework of propositions" (Novak \& Gowin, 1984, p. 15). Concept maps are created with the broader, more inclusive concepts at the top of the hierarchy, connecting through linking words with other concepts that can be subsumed. This tool helps facilitate understanding of conceptual relationships and the structure of knowledge. There is a rich history of concept mapping use and research in nursing education (Daley, Morgan \& Beman, 2016). For example, concept maps have been used as an alternative approach to nursing care plans, (Black, Green, Chapin, \& Owens, 2000), to promote critical thinking, (Daley, et al., 1999; Hicks-Moore \& Pastirik, 2006; Yeo, 2014) and to advance interdisciplinary education (Bressington, Wells \& Graham, 2011; Daley, Durning \& Torre, 2016). A newly emerging area of research, is assessing the impact of combining concept maps with high fidelity simulations in nursing education. One study found a significant correlation between nursing student self-confidence in simulation and concept maps (Samawi, Miller \& Haras, 2014).

Concept maps can also help us understand how a student's knowledge base develops and how they link theoretical understanding to practical work. Kinchin and Hay (2000, 2005) identified a qualitative classification of concept maps that included three types of maps; a spoke, a chain and a network. Each of these qualitatively different kinds of maps enhances our understanding of student learning and the development of knowledge structures leading to expertise. The "spoke" type of maps are often simple and yet, they allow the student to comfortably add new concepts to the developing knowledge base. The "chain" type of maps have many different levels and since they rely on a specific sequence the maps are hard to modify and change as the student's knowledge base grows. As Kinchin, Cabot and Hay (2008) indicated, "Chains are indicative of procedural sequences that characterize observable clinical practice" ( $p$. 94). Finally, the "network" type maps tend to be indicative of an advanced level of understanding that is more integrated and holistic. Kinchin, et al. (2008) believe that the hallmark of expertise may be the ability to move back and forth between a networked understanding of concepts and chain type of understanding and implementation in clinical practice.

Tanner's (2006) model of clinical judgment in nursing also informed this study. A major goal of simulated learning experiences in nursing education is to assist students in developing their ability to "think like a nurse" (Tanner, 2006, p. 209). In Tanner's terms, this process of thinking like a nurse is sophisticated clinical judgment that includes noticing, interpreting, responding and reflecting on clinical situations. Noticing signifies that the nurse has a perceptual grasp of the situation (Tanner, 2006, p. 208). This perceptual grasp includes the context of the situation, the

Journal of the Scholarship of Teaching and Learning, Vol. 17, No. 4, October 2017. josotl.indiana.edu 
background and the relationships that are embedded in providing nursing care. Additionally, an important component of noticing includes the expectations the nurse brings to the clinical situation. These expectations can be an understanding of the patient and the typical patient response patterns, along with the textbook knowledge of disease processes and nursing care required. Interpreting, in Tanner's model, is defined as the nurse using various reasoning patterns depending on the situation. These reasoning patterns may be analytic, intuitive or narrative. Responding, is the third phase of Tanner's clinical judgment model, and includes both actions taken and the outcomes of those actions. Finally, reflection includes both reflection-in-action within the clinical setting and reflection-on-action following a particular patient interaction. Often the reflection-on-action is triggered when the expected outcomes are not achieved.

A constructivist learning framework (Kafai \& Resnik, 2011), concept maps (Novak \& Gowin, 1984; Kinchin \& Hay, 2005), and Tanner's (2006) model of clinical judgment were all incorporated into this study. Simulated learning experiences that are carefully integrated into a nursing curriculum rely on a constructivist learning framework to assist the student in making meaning of these experiences. Additionally, simulated learning can foster the growth of students, helping them in learning to think like a nurse. Thus, the question raised in this study is, can concept maps assist in building a knowledge base, which can then be applied during simulated learning experiences, ultimately fostering the process of students' thinking like a nurse?

\section{Research Questions}

The following research questions were advanced to guide this investigation.

- How do the video recorded simulated learning experiences differ for those students who created concept maps as part of the experience versus those who did not?

- How do students describe the use of concept maps in their simulated learning experiences?

\section{Data Collection}

The students involved in this pilot study were in their senior year at a Midwestern baccalaureate nursing program. In this program, the students are divided into clinical groups of approximately eight students each. These clinical groups engage in actual practice experiences with patients in a variety of health care settings along with learning experiences in the simulation lab. Students in their clinical groups spend one half day in the simulation lab and are placed in pairs in four different simulated learning experiences while the remainder of their group with the clinical instructors observes through a video feed. These simulated learning experience are actual client case situations that involve a programmable mannequin in the role of the client. The simulations include an alcohol detoxification case, a hypoglycemic case (low blood sugar), a post-operative client who experiences severe bleeding leading to a rapidly deteriorating condition, and finally, a case involving a patient with worsening heart failure. In each of these simulated situations, the students must draw on previous knowledge and determine what nursing actions to take. Each of the simulations is video recorded. Following the simulation, the students have an opportunity to engage in a debriefing exercise with the clinical instructor. The purpose of the debriefing exercise is to discuss the process of the case, the actions in which the students engaged, and the learning that was derived from the experience. This instructor-

Journal of the Scholarship of Teaching and Learning, Vol. 17, No. 4, October 2017. josotl.indiana.edu 
led debriefing session created a situation where students could engage in reflection, the final stage of clinical judgment.

In this study, after being taught how to create concept maps, students were asked to create a concept map prior to their simulated learning experience. The students were provided with a short description of the simulated case and asked to prepare a concept map on that topic. Students then completed the simulated learning experience. Each of the simulations were video recorded. Following the simulation, the students reviewed their prepared concept maps and made changes based on learning that occurred during the simulation experience.

Students then engaged in a debriefing exercise with their clinical instructor. During this debriefing, students were asked to articulate their learning outcomes from the simulation. Additionally, students were asked about the role of the concept maps in preparing for the simulation. Post-simulation debriefings were audio recorded. At the time of the debriefing, the students were asked to submit their original concept maps including changes made following the simulation.

There were 104 students enrolled in the senior year clinical courses. All students in this semester participated in the simulated learning experiences, created concept maps and attended the debriefing sessions. However, for purposes of this study, only data from those students who consented to participate were analyzed.

Following approval by the Institutional Review Board and prior to the initiation of this study, all students received an explanation of the study. Each student received a consent form and had an opportunity to review the consent determining if they would like to have their data included in the study. Consent forms were distributed and collected by a research assistant. The principal investigator, director of the simulation lab, and the clinical instructors did not know which students had elected to participate in the study until the end of the semester. After semester grades had been completed, those students who opted out of the study had their video, audio and concept map data excluded from data analysis.

\section{Data Analysis}

Three data analysis strategies were used in this study, including analysis of the video, audio and concept maps.

First, the researchers analyzed videos of simulations from previous semesters when students had not created concept maps. The content (or case) of the simulated learning experiences in previous semesters was the same as the ones described in this study. The analysis of the videos was done based on the work of Morse and Pooler (2002). In their work with video analysis, Morse and Pooler (2002) suggest using a scaffold for analysis. "A scaffold overcomes both the threats to validity and low level analysis, while also enabling the continued use of induction within the parameters of the scaffold" (Morse \& Pooler, 2002, p. 65). To analyze the videos the researchers first reviewed all the videos for behaviors that were observed and behaviors that were missing. The purpose of this first level of analysis was to understand what happened in the case, what actions were taken by the students, and to document behaviors.

In the second level of review, the researchers then viewed the videos again, targeting observed and missing behaviors and coded these behaviors with Tanner's (2006) clinical judgment model in mind. Tanner's (2006) clinical judgment model was used as a scaffold (Morse \& Pooler, 2002) for

Journal of the Scholarship of Teaching and Learning, Vol. 17, No. 4, October 2017. josotl.indiana.edu 
data analysis. During the second level of video analysis, the researchers coded the student behaviors as noticing, interpreting, responding and reflecting.

Finally, the researchers used the same two-step process to review and code the video recorded simulations of the students who created concept maps prior to the simulation in the present semester. The coded behaviors from the group of students who did not create concept maps were then compared to the coded behavior of the student who did create concept maps. As this was a pilot study, the researchers were not blinded as to which videos were of those students who had created concept maps prior to simulation and those who had not. This should be considered a limitation of the study and addressed in future research.

Second, the researchers created transcripts of the audio recordings from the debriefing sessions. These transcripts were coded and categorized. Two researchers independently coded the transcripts specifically analyzing student learning outcomes from the simulations.

Third, two researchers independently reviewed the concept maps students created prior to the simulation and the changes they made to the maps following the simulation. The maps in this study were coded as either chains, spokes or networks according to Kinchin, Cabot and Hay (2008). The changes in the concept maps following simulation were also viewed in light of the student comments in the debriefing sessions.

To assure quality control, two researchers independently reviewed and coded each of the video recordings, audio recordings and concept maps. Comparisons revealed consistent coding across the researchers of video recordings, audio recordings and concept maps.

\section{Findings}

\section{Videos}

A total of 18 simulation videos were analyzed for this study, four simulations were of students who had not created concept maps prior to simulation and 14 videos were of students who had created concept maps prior to simulation. Observed behaviors were classified as noticing, interpreting, responding or reflecting. Table 1 compares the mean number of behaviors identified in each of these areas for both the group that created concept maps prior to simulation and the group that did not create concept maps.

\begin{tabular}{|c|c|c|}
\hline \multicolumn{3}{|c|}{$\begin{array}{c}\text { Table } 1 \\
\text { Comparison of observed simulation behaviors in groups with and without concept map } \\
\text { preparation }\end{array}$} \\
\hline $\begin{array}{c}\text { Simulation behaviors } \\
\text { observed }\end{array}$ & $\begin{array}{l}\text { Behaviors observed in } \\
\text { students with no concept } \\
\text { maps prior to simulation } \\
\quad \mathrm{N}=4 \text { videos }\end{array}$ & $\begin{array}{l}\text { Behaviors observed in } \\
\text { students with concept maps } \\
\text { prior to simulation } \\
\mathrm{N}=14 \text { videos }\end{array}$ \\
\hline Noticing & Mean $=4.2$ & Mean $=7.1$ \\
\hline
\end{tabular}

Journal of the Scholarship of Teaching and Learning, Vol. 17, No. 4, October 2017. josotl.indiana.edu 


\begin{tabular}{|l|l|l|}
\hline Interpreting & Mean $=4.2$ & Mean $=4.6$ \\
\hline Responding & Mean $=7.2$ & Mean $=7.4$ \\
\hline Reflecting & Mean $=0$ & Mean $=1$ \\
\hline
\end{tabular}

As can be seen in Table 1, mean noticing behaviors increased following the creation of concept maps. However, interpreting, responding and reflection behaviors remained rather consistent.

\section{Concept maps}

According to Kinchin and Hay (2005) concept maps can be classified into one of three categories based on their map structures. These categories include a spoke diagram in which items are seen in a single level hierarchy and are often simple. In these types of diagrams, additions do not interfere with associated concepts (Kinchin \& Hay, 2005). The chain diagram is considered compound and needs to be viewed holistically in order to make sense of the context and linkages. Chain diagrams are of many levels but it is difficult to make additions at the start of the sequence. Network diagrams are at several justifiable levels and are viewed as an expert perspective as concepts are interlinked and connected (Kinchin \& Hay, 2005).

Using the above mentioned criteria, concept maps were reviewed and categorized into one of these groups. Findings noted that 47 of the concept maps were laid out by students utilizing the spoke diagram characteristics and 25 utilized the characteristics of the network diagram. However, the spoke diagrams varied greatly in the degree and depth of the spokes. Concept maps were reviewed again after the simulation experience to see what kind of changes students made to them, noting that 23 of the concept maps had changed. Of the changes made, many of them added one spoke to their concept map. Eight of the 23 concept maps involved adding several spokes or expanding to a network pattern.

Figure 1 is a sample of a concept map a student in this study prepared prior to a simulation on caring for a patient with heart failure. Following simulation, this student added the nursing interventions of assessing pain and assessing IV fluids to their map. Figure 2 is a concept map a student prepared on the topic of diabetes. Following simulation, this student changed their concept map by adding that hypoglycemia can lead to confusion.

Journal of the Scholarship of Teaching and Learning, Vol. 17, No. 4, October 2017. josotl.indiana.edu 


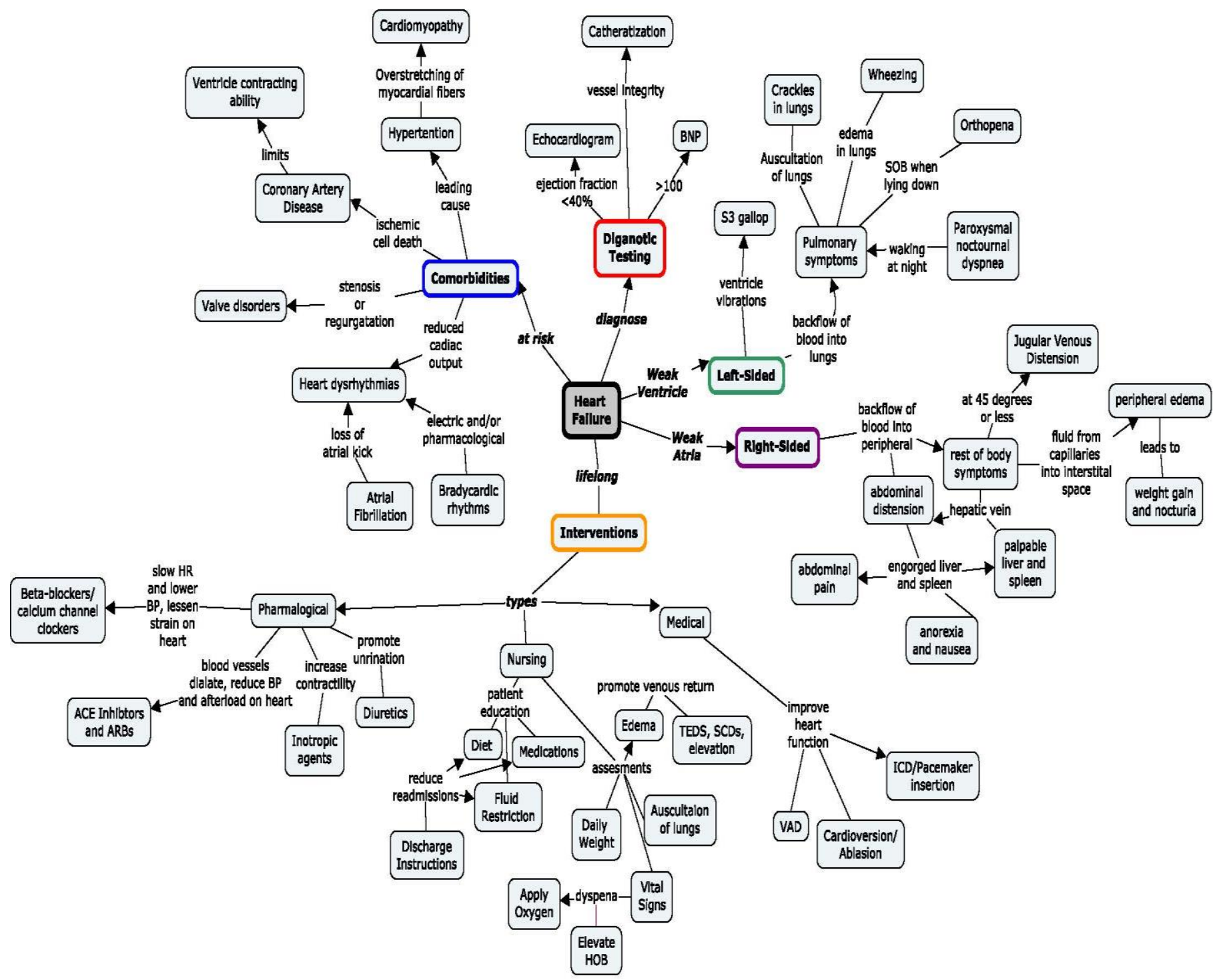

Figure 1: Sample student prepared concept map on heart failure

Journal of the Scholarship of Teaching and Learning, Vol. 17, No. 4, October 2017.

josotl.indiana.edu 


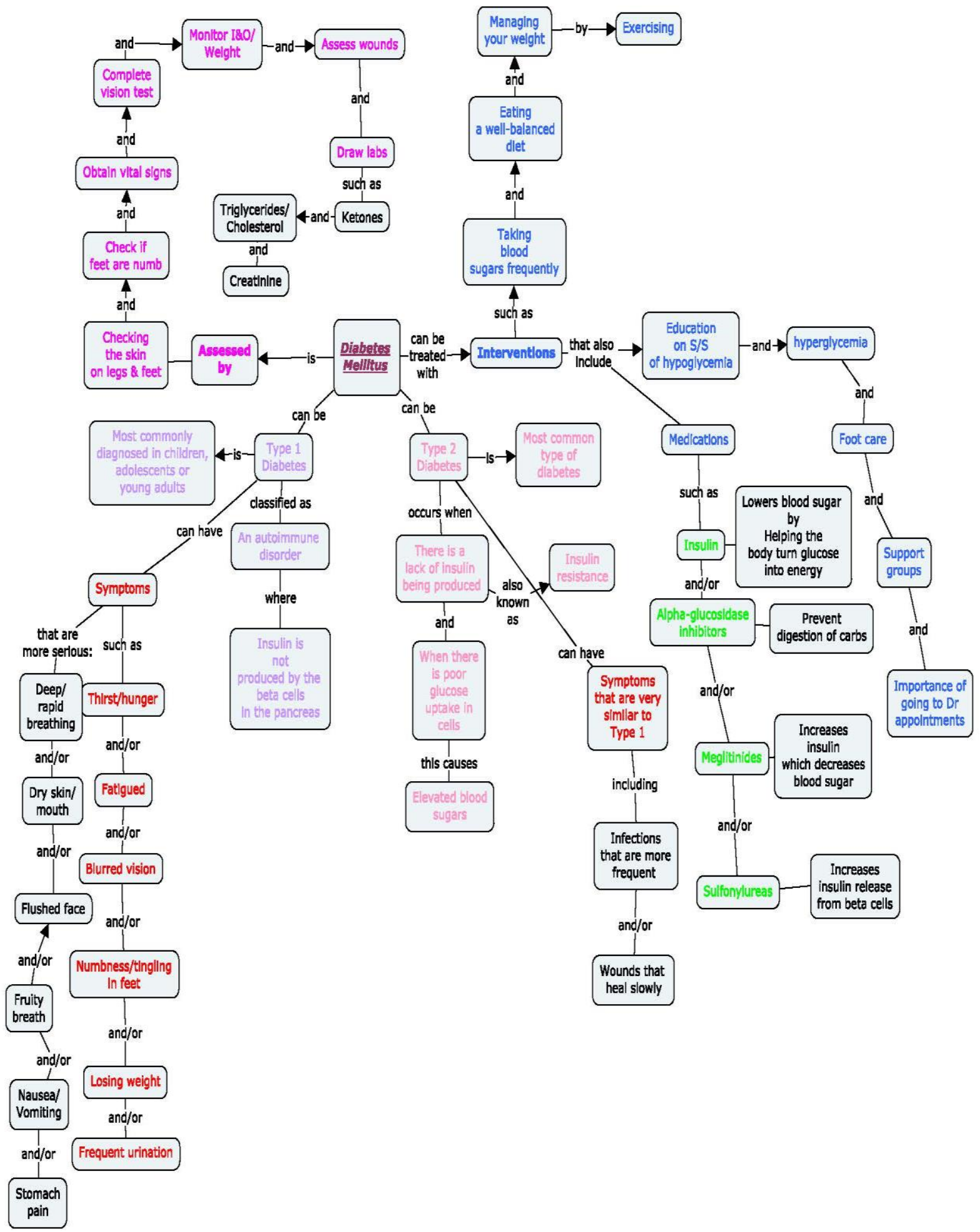

Figure 2: Sample student prepared concept map on the topic of diabetes

Journal of the Scholarship of Teaching and Learning, Vol. 17, No. 4, October 2017. josotl.indiana.edu 


\section{Debriefing sessions}

Following the high fidelity simulation, students had an opportunity to discuss the experience and debrief with their clinical instructor. The coded transcripts from these debriefing sessions indicated that students generally talked about three areas. First, the students expressed that the concept maps were helpful as a review tool. For example, students stated that the maps, "helped me remember my patho and pharm," "helped me remember my assessments," "helped me recognize the medications as I reviewed them." Students indicated that as they created the maps they were able to refresh their understanding of concepts they had learned in previous courses that would assist them in caring for the type of patient described in the simulation.

Second, students indicated that the concept maps were most helpful in increasing their understanding of complex disease processes and patient conditions. For example, students described how they felt that they had learned about diabetes in a number of different courses, and so were well familiar with the signs, symptoms, complications, patient care and patient education. So they seemed to indicate that constructing a concept map in this area was relatively straightforward. One student stated, "Doing this map I was just filling in all the information that I already knew and there wasn't anything else I was discovering; doing it differently, I would have been just as prepared if I hadn't done the map."

However, students also indicated that they always had difficulty understanding "right sided and left sided heart failure" so that having to create a concept map in this area was valuable and helped them differentiate between the two. Additionally, students expressed that doing the concept maps helped them bring together their clinical and classroom experiences. One student when asked what she thought of creating concept maps for simulation stated, "I think it helped, I mean, because on the unit we're at you deal with like a lot of heart things. So it kind of helped to bring our experience from clinical and put it on paper."

Finally, students shared how the maps would have been more helpful if they had been introduced earlier in their curriculum. Students indicated that in their senior year of a nursing program, their study strategies were pretty well ingrained, and they wished they had learned about concept mapping earlier in their program. Additionally, in one of the groups a clinical instructor had been using concept maps, so students in that group were well accustomed to creating maps and they immediately expressed advantages in creating maps for simulation.

\section{Discussion and Implications}

This pilot study has a number of implications for high fidelity simulations, nursing curriculum and the creation of knowledge structures. Additionally, this initial study indicates a need for further research in this area.

First, in this study nursing students who had prepared concept maps prior to engaging in simulation, demonstrated an increase in noticing behaviors. However, because this was a small pilot study the sample size was not large enough to determine statistical significance and thus should be considered a limitation of the study. Despite this limitation, the increase in noticing behaviors was evident. It appears that the noticing behaviors increased because the concept maps

Journal of the Scholarship of Teaching and Learning, Vol. 17, No. 4, October 2017. josotl.indiana.edu 
served to refresh students' memories of pathophysiology, pharmacology, disease processes, signs/symptoms and assessment skills. Additionally, the concept maps seemed to support students linking their clinical experiences with their classroom experiences thus enhancing both. In this study, the students only created two concept maps in preparation for simulation, which leads to the question if additional concept maps were created would this lead to more changes in interpreting, responding and reflecting behaviors? Additionally, could the assignment for preparing the concept maps prior to simulation, include directions that would help the students think through and include on their maps more interpretation and responding interventions? Finally, the vast majority of students in this study created spoke type concept maps (as seen in Figures 1 and 2), and following the simulation added more spokes to their map. This leads to the question do the spoke type maps facilitate noticing behaviors within simulations? If students had more experience in concept mapping and were creating more network type of maps, would this lead to an increase in interpreting, responding and reflecting behaviors? Additional research in how concept maps can be used to prepare for simulation is needed along with research that explores how the maps facilitate the development of clinical judgment.

Second, students in this study clearly identified that learning how to do concept maps earlier in their nursing education would have been valuable. Additionally, the one clinical group in this study that had previous experience in creating concept maps saw great value in their use in preparation for simulation. Future research needs to investigate the most appropriate placement of concept maps in nursing curricula. Should concept maps be introduced in theory courses, in clinical courses or both? How could concept maps be effectively integrated across nursing curricula?

Finally, this study has implications for how nursing students create knowledge structures. Students in this study discussed how the concept maps were helpful in understanding complicated disease processes and how the maps helped them remember concepts and link their clinical and classroom experiences. By contrast, within seminal medical education research, there is evidence that although the quantity of knowledge medical students possess is at an appropriate level, their level of knowledge organization may be poor, thus affecting their ability to solve problems and achieve a correct diagnosis (Bordage, 1994). Groves et al. (2003) demonstrated that medical students' clinical reasoning process might be somewhat underdeveloped, in particular, as related to their knowledge structures, which may not yet be developed in such a way as to allow accurate synthesis and correct diagnoses.

It appears in this study, that the concept maps assisted nursing students to organize their knowledge structures, in a way that increased the applicability in the simulated setting and increased their noticing behaviors. Additionally, students continued the process of developing their knowledge structure following the simulation experience when they continued to add more "spokes" to their original concept map thus refining and enhancing their knowledge. However, more research is needed to verify and validate this preliminary finding.

\section{Summary}

Research in nursing education linking concept mapping and high fidelity simulation is new. There is a great need for future studies in this area to determine the role that concept mapping may be

Journal of the Scholarship of Teaching and Learning, Vol. 17, No. 4, October 2017. josotl.indiana.edu 
able to play in helping prepare students for simulations, as well as, clinical nursing practice. Concept mapping may be able to assist students in developing sophisticated knowledge structures that can be accessed in simulation and eventually clinical practice. If this is the case, then mapping has the potential to assist students in developing their ability to "think like a nurse."

\section{Acknowledgements}

This study was supported by resources from the Wisconsin Teaching Fellows and Scholars Program, which is part of the Office of Professional and Instructional Development of the University of Wisconsin System.

Journal of the Scholarship of Teaching and Learning, Vol. 17, No. 4, October 2017. josotl.indiana.edu 


\section{References}

Barr, R. B., \& Tagg, J. (1995). From teaching to learning: A new paradigm for undergraduate education. Change: The Magazine for Higher Learning, 27(6), 12-26.

Black, P., Green, N., Chapin, B., \& Owens, C. (2000). Concept mapping: An alternative teaching strategy. Pelican News: Louisiana State Nurses Association, 56(4).

Bordage, G. (1994). Elaborated knowledge: A key to successful diagnostic thinking. Academic Medicine, 69, 883-885.

Bressington, D. T., Wells, H., \& Graham, M. (2011). A concept mapping exploration of social workers' and mental health nurses' understanding of the role of the Approved Mental Health Professional. Nurse Educ Today, 31(6), 564-570. doi:10.1016/j.nedt.2010.10.034

Daley, B.J. \& Morgan, S. \& Beman, S. (2016). Concept maps in nursing education: A historical review and research directions. Journal of Nursing Education, 55(11), 631-639.

Daley, B. J., During, S., \& Torre, D.M. (2016). Using Concept Maps to Create Meaningful Learning in Medical Education. MedEdPublish, 5(1), 19. Dundee, UK: The Association for Medical Educators in Europe (AMEE). http://www.mededpublish.org/manuscripts/380/ DOI: http://dx.doi.org/10.15694/mep.2016.000019

Daley, B. J., Shaw, C. R., Balistrieri, T., Glasenapp, K., \& Piacentine, L. (1999). Concept maps: A strategy to teach and evaluate critical thinking. Journal of Nursing Education, 38(1), 42-47.

Gaba, D. M. (2004). The future vision of simulation in health care. Quality \& Safety in Health Care, 13 (Suppl 1)(12-1-10). doi:10.1136/qshc.2004.009878

Groves, M., O'Rourke, P., \& Alexander, H. (2003). Clinical reasoning: The relative contribution of identification, interpretation and hypothesis errors to misdiagnosis. Medical Teacher, 25, 621625 .

Hicks-Moore, S. L., \& Pastirik, P. (2006). Evaluating critical thinking in clinical concept maps: A pilot study. International Journal of Nursing Education Scholarship, 3(1), Article 27. DOI: $\underline{10.2202 / 1548-923 X .1314}$

Hutchings, P., \& Cambridge, B. (1999). Your invitation to participate in the Carnegie Teaching Academy Campus Program. Washington, DC: American Association for Higher Education and the Carnegie Foundation for the Advancement of Teaching.

Kafi, Y., \& Resnik, M. (Eds.). (2011). Constructionism in practice: Designing, thinking and learning in a digital world. New York, New York: Routledge.

Journal of the Scholarship of Teaching and Learning, Vol. 17, No. 4, October 2017. josotl.indiana.edu 
Kinchin, I., Cabot, L. B., \& Hay, D. (2008). Using concept mapping to locate the tacit dimensions of clinical expertise: Towards a theoretical framework to support critical reflection on teaching. Learning in Health and Social Care, 7(2), 93-104.

Kinchin, I., \& Hay, D. (2005). Using concept maps to optimize the composition of collaborative student groups: A pilot study. Journal of Advanced Nursing, 51(2), 182-187.

Kinchin, I., M, \& Hay, D. B. (2000). How a qualitative approach to concept map analysis can be used to aid learning by illustrating patterns of conceptual development. Educational Research 42, 42(1), 43-57.

Lambert, L., Walker, D., Zimmerman, D., Cooper, J., Lambert, M. D., Gardner, M. E., \& FordSlack, P. J. (1995). The constructivist leader. New York: Teachers College Press.

Morse, J. M., \& Pooler, C. (2002). Analysis of videotaped data: Methodological considerations. International Journal of Qualitative Methods, 1(4), 62-67.

Novak, J. D. (1998). Learning, creating and using knowledge: Concept maps as tools to understand and facilitate the process in schools and corporations. New York, New York: Lawrence Earlbaum Associates.

Novak, J. D., \& Gowin, B. (1984). Concept mapping for meaningful learning. Learning How to Learn (pp. 15-54). London, England: Cambridge University Press.

National Council of State Boards of Nursing. (2014). The NCSBN national simulation study: A longitudinal, randomized, controlled study replacing clinical hours with simulation in prelicensure nursing education. Journal of Nursing Regulation, Supplement, 5(2), S4-S64. Retrieved from: https://www.ncsbn.org/JNR_Simulation_Supplement.pdf

Samawi, Z., Miller, T., \& Haras, M. S. (2014). Using high-fidelity simulation and concept mapping to cultivate self-confidence in nursing students. Nursing Education Perspectives, 35(6), 408-409.

Schulman, L. A. (2005). Signature pedagogies in the professions. Daedalus, 134(3), 52-59.

Tanner, C. (2006). Thinking like a nurse: A research-based model of clinical judgment in nursing. Journal of Nursing Education, 45(6), 204-211.

Yeo, C. M. (2014). Concept mapping: A strategy to improve critical thinking. Singapore Nursing Journal, 41(3), 2-7.

Journal of the Scholarship of Teaching and Learning, Vol. 17, No. 4, October 2017.

josotl.indiana.edu 